\title{
Financial Strain, Parenting Behaviors, and Adolescents' Achievement: Testing Model Equivalence between African American and European American Single- and Two-Parent Families
}

\author{
Leslie Morrison Gutman and Jacquelynne S. Eccles
}

\begin{abstract}
This study tested the equivalence of a theoretical model of parenting behaviors linking financial strain to adolescents' achievement for African American and European American families and for single- and two-parent families. The sample included an economic cross-section of African American $(n=387)$ and European American families $(n=230)$ from single- $(n=171)$ and two-parent $(n=446)$ homes. Multi-group analyses revealed no significant differences in the structural equation models between the African American and European American families, or between the single- and two-parent families. Results demonstrated that negative parent-adolescent relationships and parental school involvement mediated the relation between financial strain and adolescents' academic achievement.
\end{abstract}

\section{INTRODUCTION}

In the past decade, the poverty rate in the United States has reached its highest level in 20 years; the number of children whose families live in poverty has increased from $15 \%$ in 1970 to $22 \%$ in 1994 (U.S. Bureau of the Census, 1996). These trends have precipitated renewed interest among researchers in the impact of economic hardship on families and children (McLoyd, 1990). Evidence documenting the negative role poverty plays in the lives of many American children continues to accumulate. Children who are living in poverty are at greater risk for experiencing an array of academic, socioemotional, behavioral, and health problems that can have deleterious effects on their long-term developmental trajectories (McLoyd, 1990, 1998).

Poverty affects children not only directly, by limiting material resources, but also indirectly through the distress it creates for parents, which in turn undermines parents' capacity for supportive, involved, and consistent parenting (McLoyd, 1990, 1998). The general framework for understanding the mediational role that family processes play in linking economic hardship to children's outcomes is drawn from Elder's studies of European American families of the Great Depression (Elder, 1974; Elder, Van Nguyen, \& Caspi, 1985). In these studies, Elder and his colleagues found few direct effects of economic hardship on children's behavior and socioemotional functioning. Rather, adversity was produced indirectly through negative effects on fathers' psychological functioning and parenting behaviors. Fathers who sustained heavy financial loss became more irritable, tense, and explosive, which increased their tendency to be punitive, rejecting, and inconsistent in disciplining their children. In turn, these negative fathering behaviors were predictive of several emotional difficulties in children. Studies with more recent samples have found similar results for children's socioemotional outcomes such as depression, competence, self-esteem, and anxiety; and behavioral outcomes such as drug and alcohol use, delinquency, and antisocial behavior (e.g., Conger, et al., 1992; Conger, Ge, Elder, Lorenz, \& Simons, 1994; Conger, et al., 1991; Dodge, Pettit, \& Bates, 1994; Furstenberg, Cook, Eccles, Elder, \& Sameroff, 1999; Harold-Goldsmith, Radin, \& Eccles, 1988; Lempers, Clark-Lempers, \& Simons, 1989; McLoyd, Jayaratne, Ceballo, \& Borquez, 1994).

Although fewer in number, several studies have also examined the family processes linking economic hardship to children's achievement. For example, Hess and Holloway (1984) found a number of parenting behaviors linking socioeconomic variables to children's school performance, including verbal exchanges between parents and children, parental expectations for achievement, positive affective relationships between parents and children, and discipline and control strategies. Similar results have been reported in more recent studies (Conger, Conger, \& Elder, 1997; Conger et al., 1992; Furstenberg et al., 1999; Korenman, Miller, \& Sjaastad, 1995; Lee \& Croninger, 1994). For example, in a sample of European American twoparent families of adolescent boys, Conger and colleagues (1992) found that economic pressures were significantly associated with depression and demoralization in parents; these, in turn, were related to dis-

(C) 1999 by the Society for Research in Child Development, Inc. All rights reserved. 0009-3920/99/7006-0014 
ruptions in such parenting behaviors as involvement, warmth, and discipline practices that were consistent and not overly harsh. These disrupted parenting practices mediated the relation between parents' depressed mood and adolescents' positive adjustment, including performance in their school. In a subsequent study using the same sample, Conger and colleagues found that the effects of economic conditions on adolescents' school performance were largely accounted for by the economic pressures these conditions created as well as parents' responses to these pressures (Conger et al., 1997).

The studies mentioned above have provided excellent theoretical models describing the mediating role of family processes in linking economic resources to children's and adolescents' outcomes. To our knowledge, however, the authors have focused almost exclusively on within-group analyses. That is, they have examined primarily either African American or European American families and either single- or twoparent families. Consequently, we do not know how robust their findings are across different ethnic groups and family structures. The present study extends these previous findings by assessing the role that parenting behaviors play in linking financial strain to adolescents' academic achievement for African American and European American families and for singleand two-parent families.

There are several reasons for testing the empirical adequacy of a mediational model of financial strain, parenting behaviors, and adolescents' academic achievement for both African American and European American families. First, factors associated with ethnicity, such as duration and timing of poverty and differences in economic resources, are likely to modify parents' responses to economic loss (McLoyd, 1990). For example, African American families with children are more likely to live in poverty, and for longer periods of time, than are European American families with children (Brooks-Gunn, Duncan, \& Maritato, 1997). Second, poverty among African American families, unlike European American families, is complicated by racism (McLoyd, 1990). Factors linked to past and present racial discrimination (e.g., housing patterns, neighborhood resources, and restricted educational and employment opportunities) create disparities between the resources available to poor African American and those available to poor European American families. For instance, poor African American families are more likely to reside in concentrated poor, isolated urban neighborhoods than are poor European American families (Wilson, 1987). Such differences in available resources are likely to make parenting more difficult for African American families experiencing financial strain. Third, the effectiveness of specific parenting practices on children's competence may vary from one ethnic group to another (e.g., Baumrind, 1972; Dornbusch, Ritter, Leiderman, Roberts, \& Fraleigh, 1987). For example, some evidence suggests that authoritative parenting (i.e., parenting high in parenting family decision-making and communication, clear in setting rules, and uses commands and sanctions when necessary) may be a stronger predictor of academic achievement for European American adolescents than for African American adolescents (Dornbusch et al., 1987).

There are also several important reasons for testing the equivalence of this mediational model for both single- and two-parent families. First, psychological distress is high in environments where there is no marital partner to provide emotional and financial support. Moreover, single mothers are at greater risk for psychological distress and anxiety than are other marital status groups, especially if they are living in poverty (McLoyd, 1990). Consequently, single-parent families may experience a greater sense of financial strain in response to low income than do two-parent families. Second, considering that mothers assume the role of custodial parent in all but a few single-parent families and often represent the only source of income for those families (McLoyd, 1990), financial strain may be a stronger predictor of parenting behaviors and children's functioning in single-parent families than in two-parent families.

To a limited extent, the similarity among findings in studies linking economic hardship to children's outcomes mitigates the issue of generalizability across African American and European American families and across single- and two-parent families. Yet, we know of no studies that empirically test the equivalence of a mediational model of financial strain, parenting behaviors, and adolescents' achievement for African American and European American families and for single- and two-parent families. Therefore, using LISREL VIII, we impose equality constraints on the structural equation models of African American and European American subsamples and single- and twoparent subsamples, thereby allowing a more sensitive assessment of group differences.

Drawing on past research, we propose a processbased theoretical model linking economic resources to adolescents' academic achievement. First, as shown in Figure 1, we postulate that total family income will be directly associated with financial strain conceptualized in terms of the degree to which parents report (1) not having enough money to make ends meet, and (2) worrying about not having enough money. We also predict that total family income will affect 


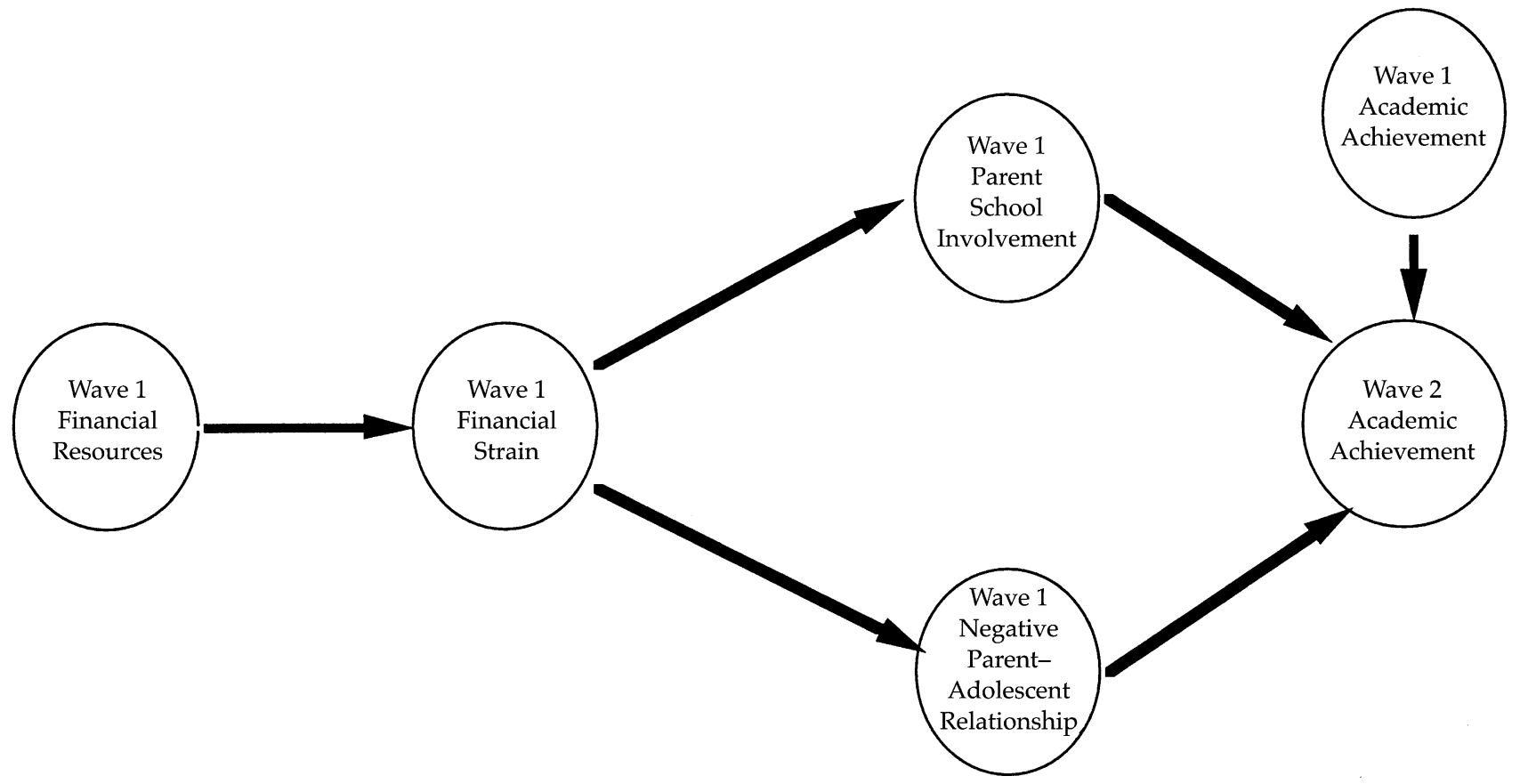

Figure 1 The theoretical model.

parenting behaviors through its impact on parents' sense of financial strain. Previous studies have demonstrated that adverse economic conditions such as low income influence family relationships primarily through the financial strains or economic pressures they create in family life (Conger et al., 1997, 1992, 1994; Elder, Eccles, Ardelt, \& Lord, 1995; Furstenberg et al., 1999; McLoyd et al., 1994; Simons, Lorenz, Conger, \& Wu, 1992).

As shown in Figure 1, we also predict that (1) the financial strain created by low family income will increase the likelihood of negative parent-adolescent relationships conceptualized in terms of conflict and harsh discipline; and (2) negative parent-adolescent relationships will undermine adolescents' academic achievement. According to Patterson (1982), family conflict and expressions of hostility often occur when family members experience stressful environmental conditions. Research has demonstrated that economic stress is an environmental factor that increases the likelihood of such negative family interactions as parents' hostility, parent-adolescent conflict, and parents' use of harsh discipline, which in turn negatively impact children's and adolescents' socioemotional functioning and positive adjustment (Conger et al., 1997, 1992, 1994; Furstenberg et al., 1999; McLoyd et al., 1994).

Although most of the previous studies have examined how family coercive processes mediate children's emotional well-being, a more recent study examined how they influence adolescents' academic achievement (Conger et al., 1997). In this study of two-parent, European American families, mothers' harsh, inconsistent parenting (rated by an observer) negatively affected adolescents' self-confidence, which in turn adversely impacted their grade point averages. Similar results are reported by Furstenberg et al. (1999) for a predominately African American sample. In our study, we extend the scope of this research by examining whether negative parent-adolescent relationships mediate the link between financial strain and adolescents' academic achievement in different ethnic groups and family structures.

As shown in Figure 1, we also predict that financial strain created by low family income will negatively influence parental school involvement, which in turn will adversely affect adolescents' academic achievement (Clark, 1983; Comer, 1980; Eccles \& Harold, 1993; Epstein, 1987, 1990). Since parental school involvement requires both time and patience-qualities in short supply for poor parents who often feel hassled and overburdened-parents who experience economic stress tend to be less involved in the school activities of their children and adolescents (McLoyd, 1990). Parents living in poor communities also often feel that their involvement is less efficacious, and may have had negative interactions with teachers and school personnel that leave them feeling suspicious of, and disaffected 
from, their children's school (Comer, 1983; Eccles \& Harold, 1993). Although evidence indicates that parents' involvement in their children's education varies widely among ethnic and income groups, which may help explain differential achievement levels (Carnegie Council on Adolescent Development, 1995; Clark, 1983; Comer, 1980; Eccles \& Harold, 1993; Epstein, 1987, 1990), few studies have examined the relations between economic resources, parental school involvement, and children's academic achievement. In our study, we extend the scope of this research by examining the mediational role of parental school involvement linking financial strain to adolescents' academic achievement in different ethnic groups and family structures.

In the following analyses, we test the empirical adequacy of this postulated model of financial strain, parenting behaviors, and adolescents' academic achievement for African American and European American families, and for single- and two-parent families (see Figure 1). Our model includes direct paths from Wave 1 (the first data collection period) financial strain to Wave 1 parenting measures to adolescents' achievement at Wave 2 (approximately 2 years later), strengthening inferences regarding likely causal direction and decreasing within-wave reporter bias. To control for prior achievement, we include adolescents' achievement at Wave 1 as a control variable.

This study extends previous studies of economic hardship by (1) examining whether negative parentadolescent relationships and parental school involvement link financial strain to adolescents achievement over time, (2) testing the equivalence of this model for African American and European American families, and (3) testing the equivalence of this model for both single- and two-parent families. We used a multiinformant study design because this improves the measurement model and the estimation of relations among the theoretical constructs, and addresses the problems of single respondent bias.

\section{METHOD}

\section{Participants}

The subjects for this study are part of the Maryland Adolescent Development in Context (MADIC) study. MADIC is an ongoing, longitudinal study of adolescents, their families, and their schools in a large county in Maryland. Families were recruited through public junior high schools. In the fall of 1991, a brief description of the study was sent home with each seventh grader in the county. Families who were interested in learning more about the study were asked to sign and return a form giving the study staff permission to contact them. Of these families, 76\% (1357 African American and European American families) participated in the first wave of data collection. Most of the families that chose not to participate declined due to time constraints, scheduling conflicts, or lack of interest; some were never reached due to difficulties obtaining current phone and address information. Because the schools did not permit contact with the families that failed to return the permission slip, their nonparticipation was unexplained.

In the summer and fall of 1993, following the target adolescent's eighth-grade year, a total of 959 African American and European American families participated in the second wave of data collection. Of the 398 families who participated in Wave 1 but did not participate in Wave 2, 47\% refused to participate, 29\% had moved to another location, and $23 \%$ were unable to schedule an appointment. The issue of differential attrition from Wave 1 to Wave 2 was examined with $t$ tests contrasting these two groups' scores on Wave 1 predictor and outcome variables. Results showed that families with both waves of data had more income, higher levels of parental school involvement, and higher grade point averages than did families with data only at Wave 1. Eta-squares for these analyses, however, were modest (.00 to .016), indicating that the difference accounted for only $1-2 \%$ of the variance. These families did not significantly differ in the amount of money they had left at the end of the month, financial worries, or negative parent-adolescent relationships.

In the study reported here, families whose marital status changed between Wave 1 and Wave $2(n=65)$ were not included in the analyses. Of the 894 families who met the study criteria, complete data were available for a total of 617 families (387 African American and 230 European American families; 446 twoparent and 171 single-parent families; $69 \%$ of the eligible families).

Listwise deletion of data was examined by comparing the families for whom complete data were available $(n=617)$ with the families for whom the data was incomplete $(n=894)$. Results of $t$ tests contrasting these two groups' scores on all the predictor and outcome variables showed that families for whom complete data were available had more income, higher levels of parent-reported parent-adolescent conflict, and higher grade point averages than did families with incomplete data. Eta-squares for these analyses, however, were modest (.00 to .024), indicating that the difference accounted for only $1-2 \%$ of the variance. Families did not significantly differ in any of the other variables.

For the 617 families, median income in this study 
Table 1 Demographic Characteristics of the Sample $(N=617)$

\begin{tabular}{|c|c|c|c|c|c|}
\hline Demographic Variable & Mean & Median & $S D$ & Minimum & Maximum \\
\hline 1. W1 family income $\mathrm{a}^{\mathrm{a}}$ & 10.06 & 10.00 & 4.11 & 1.00 & 16.00 \\
\hline 2. W1 primary caregiver's occupational prestige score & 262.61 & 276.00 & 187.16 & 5.00 & 877.00 \\
\hline 3. W1 secondary caregiver's $\mathrm{s}^{\mathrm{b}}$ occupation prestige score & 356.75 & 356.50 & 269.87 & 1.00 & 889.00 \\
\hline 4. W1 primary caregiver's education ${ }^{c}$ & 13.83 & 14.00 & 2.26 & 5.00 & 26.00 \\
\hline 5. W1 secondary caregiver's education ${ }^{\text {bc }}$ & 14.23 & 14.00 & 2.78 & 5.00 & 26.00 \\
\hline 6. W1 primary caregiver's age & 39.94 & 39.62 & 6.62 & 28.13 & 74.71 \\
\hline 7. W1 secondary caregiver's age ${ }^{b c}$ & 41.07 & 41.86 & 8.76 & 15.87 & 67.57 \\
\hline 8. W1 adolescent's age ${ }^{\mathrm{c}}$ & 12.24 & 12.00 & .55 & 11.00 & 16.00 \\
\hline 9. W2 adolescent's age ${ }^{c}$ & 14.18 & 14.13 & .45 & 13.31 & 16.01 \\
\hline 10. W1 number of children & 1.85 & 4.00 & 1.04 & 1.00 & 7.00 \\
\hline
\end{tabular}

a $1=<\$ 5,000,2=\$ 5,000-\$ 9,999,3=\$ 10,000-\$ 14,999,4=\$ 15,000-\$ 19,999,5=\$ 20,000-\$ 24,999,6=\$ 25,000-\$ 29,999,7=\$ 30,000-$ $\$ 34,999,8=\$ 35,000-\$ 39,999,9=\$ 40,000-\$ 44,999,10=\$ 45,000-\$ 49,999,11=\$ 50,000-\$ 54,999,12=\$ 55,000-\$ 59,999,13=\$ 60,000-$ $\$ 64,999,14=\$ 65,000-\$ 69,999,15=\$ 70,000-\$ 74,000,16=>\$ 75,000$.

${ }^{b}$ Includes only those families with secondary caregivers.

${ }^{c}$ Age given in years.

from all sources for the year prior to the first wave of data (1990) was between $\$ 45,000$ and $\$ 49,999$ (see Table 1). There was a wide range of income distribution: $15 \%$ reported incomes less than $\$ 25,000,35 \%$ between $\$ 25,000$ and $\$ 50,000,25 \%$ between $\$ 50,000$ and $\$ 65,000$, and $25 \%$ above $\$ 65,000$. Caregiver occupations ranged from professional, requiring advanced degrees, to unskilled. Occupational prestige scores (from 1 = most prestigious to $999=$ least prestigious) for primary and secondary caregivers revealed that both caregivers were generally semiprofessional or skilled workers (see Table 1). This sample clearly contained sufficient variability in family income and occupation levels to test the impact of differing economic circumstances on family processes and adolescent outcomes.

Although the African American and single-parent families did have slightly lower mean levels of income than did the European American and two-parent families, respectively (see Tables 3 and 4), the variability in income distribution within all four groups was sufficient to test the proposed model. For example, of the African American families, 20\% reported incomes less than $\$ 25,000,40 \%$ between $\$ 25,000$ and $\$ 50,000,17 \%$ between $\$ 50,000$ and $\$ 65,000$, and $23 \%$ above $\$ 65,000$. Of the single-parent families, $32 \%$ had incomes less than $\$ 25,000,53 \%$ between $\$ 25,000$ and $\$ 50,000,10 \%$ between $\$ 50,000$ and $\$ 65,000$, and $5 \%$ above $\$ 65,000$.

\section{Procedure}

For both waves of data, interviewers from the local area met with each of the families. The MADIC staff trained all interviewers during a three-day workshop. The racial composition of the interviewers roughly matched that of the county at large $(60 \%$ African American, 38\% European American, 2\% Hispanic), and most interviewers were women. Interviewers were paid on a per-interview basis. To ensure that interviewers followed the interview protocol accurately, $15 \%$ of the families were randomly recontacted by the study staff to verify that the interview had taken place, that all of the questions had been asked, and that the interviewer had behaved professionally while in the family's home. These verification calls revealed no problems with the interview staff.

In each family, the primary caregiver and target adolescent were interviewed and then given a questionnaire to complete on their own. In many families, a secondary caregiver and/or older sibling also completed a self-administered questionnaire. The primary caregiver was identified during the initial telephone contact. The interviewer phoned the household and asked to speak with the parent identified by the school, generally the mother. After describing the study and obtaining the caregiver's agreement to participate, the interviewer asked this adult, "Out of the people living in this household, what is the name of the person who has the most responsibility for and knows the most about (the target adolescent)?" The person named in response to this question was identified as the primary caregiver. The majority of primary caregivers were either mothers $(86 \%)$ or fathers $(7 \%)$ of the target adolescents, but primary caregivers also included grandparents and other relatives. Although not all of the primary caregivers were parents of the target adolescents, the terms parent and primary caregiver are used interchangeably in this study.

The secondary caregiver was also identified dur- 
ing the initial telephone call. The majority of secondary caregivers were either fathers/stepfathers $(77 \%)$ or mothers/stepmothers $(7 \%)$ of the target adolescents, but secondary caregivers also included siblings, grandparents, and other relatives. Eighty-seven percent of the secondary caregivers were married to the primary caregivers.

Following the initial telephone contact, the remainder of the interview process took place in the home of the family. As stated, the parent and target adolescent were asked to complete two booklets, one during a face-to-face structured interview and one on their own. During the first portion of the interview, the adolescent completed the self-administered booklet in a quiet, private place, while the interviewer was administering the face-to-face portion to the parent. For the second portion of the interview, these positions were reversed. For both face-to-face interviews, a card containing all relevant response scales was given to the respondent. Interviewers referred respondents to this card rather than reading each response scale to the respondent. Interviewers also were instructed to read all the questions exactly as written in the books, and not to define words or interpret questions for the respondents.

Each face-to-face interview took approximately $1 \mathrm{hr}$ and each self-administered booklet took approximately $30 \mathrm{~min}$ to complete. Target adolescents and parents were each given $\$ 15$ for their participation.

\section{Measures}

The following description of the measures follows the model presented in Figure 1 from left to right. As Bank, Dishion, Skinner, and Patterson (1990) recommend, we used different reporters whenever possible, from across and within our constructs, to minimize biases in the estimates of path coefficients from single sources of information. For example, for negative parent-adolescent relationships, we used reports from both parents and adolescents. For some indicators, however, we had only one source. For instance, grade point average, an indicator of achievement, was obtained only from school records. In addition, reports of parental school involvement were obtained from the parents only.

We also used measures from both Waves 1 and 2 to strengthen inferences regarding likely causal direction and to decrease within-wave reporter bias. Since Wave 1 financial resources represented family income for the previous year, our model included direct paths from Wave 1 financial resources to Wave 1 financial strain to Wave 1 parenting behaviors to adolescent achievement at Wave 2. To control for prior achieve- ment, we also included adolescent achievement at Wave 1.

Wave 1 financial resources. A single indicator, family income, was used to represent financial resources. Family income comprised the total family income before taxes from all sources in the previous year (1990). In two-parent families where the primary and secondary caregivers were married and both participated, the total family income was derived by averaging the incomes reported by the primary and secondary caregivers; these were highly correlated, $r(446)=.79, p \leq$ .001. In single-parent families or families where the secondary caregiver lived in another household or did not participate, the total family income was obtained from the primary caregiver only.

Wave 1 financial strain. Two indicators were used to assess financial strain. The first indicator was whether parents felt they had money left over at the end of the month to make ends meet $(1=$ more than enough money, $4=$ not enough money). The second indicator was whether parents had worries about money $(1=$ not worried at all, $4=$ very upset or worried). In twoparent families where the primary and secondary caregivers were married and both participated, these indicators were derived by averaging the reports of the primary and secondary caregivers, which were significantly correlated, $r(446)=.33, p<.001$ and $r(446)=$ $.33, p<.001$, respectively. In single-parent families or families where the secondary caregiver lived in another household or did not participate, only the reports of the primary caregivers were used.

Wave 1 negative parent-adolescent relationships. Two constructs were used as indicators of negative parent-adolescent relationships. Both the primary caregivers and adolescents reported parent's use of harsh discipline strategies, including hitting, threatening to hit, and yelling $(1=$ not at all, $5=$ almost always). The $\alpha$ for the 3 -item scale was .86 for primary caregivers and .80 for adolescents. The primary caregivers and adolescents also reported on the frequency of parent-adolescent conflict, including conflicts about money, time spent outside of school, grades, and how the adolescents dressed or wore their hair $(1=$ not at all, $5=$ almost always $)$. The $\alpha$ for the 4-item scale was. 77 for primary caregivers and .76 for adolescents.

Wave 1 parental school involvement. Three indicators were used to assess parental school involvement. Primary caregivers reported the number of times they volunteered in the classroom, attended a Parent-Teacher Association meeting, and attended an open house.

Wave 1 and Wave 2 academic achievement. A single indicator, grade point average, was used to measure academic achievement range $=1.0-5.0)$. Grades were 
averaged for only the core academic courses such as English, math, science, and foreign language. Grades were obtained from school records at Wave 1 and Wave 2 for each student.

\section{RESULTS}

\section{Correlational Analyses}

Table 2 contains the correlations among all variables used in testing the theoretical model. Intercorrelations among indicators within constructs are in bold typeface. For the most part, correlations between measures within constructs were higher than those across constructs. For example, the intercorrelations among the indicators for Wave 1 negative parentadolescent relationships ranged from .19 (adolescent report of harsh discipline and parent report of conflict) to .36 (parent report of conflict and parent report of harsh discipline). The intercorrelations among the indicators for Wave 1 parental school involvement ranged from .41 (involvement in the classroom and involvement in open house) to .62 (involvement in PTA and involvement in open house). Intercorrelations among indicators for different reporters within the same construct were also higher than were those across constructs. For example, the intercorrelations among the indicators for Wave 1 negative parentadolescent relationships were .34 and .33 for the parent and adolescent reports of harsh discipline and parent-adolescent conflict, respectively.

Furthermore, the correlations among indicators across constructs provided some preliminary evidence for the hypothesized model. For example, with the exception of the adolescent report of conflict, all of the indicators of Wave 1 negative parent-adolescent relationships and Wave 1 parental school involvement correlated significantly with at least one of the indicators of Wave 1 financial strain. Similarly, Wave 1 family income and all the indicators of Wave 1 financial strain, Wave 1 negative parent-adolescent relationships, and Wave 1 parental school involvement correlated significantly with adolescents' grade point average at Wave 1 and Wave 2. Taken together, these correlations supported a more formal test of the theoretical model.

We also examined the correlations among parents' education and occupational prestige score and the indicators and outcomes. As expected, education and occupational prestige score were highly correlated with family income and the indicators of financial strain. Education and occupational prestige score, however, were not significantly correlated with the indicators of negative parent-adolescent relationships and parental school involvement. Although education significantly correlated with adolescents' grade point average, occupational prestige score was not. This is consonant with evidence that among the traditional indicators of SES, family income is the single most important predictor of school performance and that in analyses combining income, occupation, and education, results are only slightly more correlated with academic achievement than are those for income alone (see McLoyd, 1998). For these reasons, we did not include parents' education or occupational prestige score in our model.

Table 2 Correlation Coefficients, Means, and Standard Deviations for All Study Variables

\begin{tabular}{|c|c|c|c|c|c|c|c|c|c|c|c|c|c|}
\hline & 1 & 2 & 3 & 4 & 5 & 6 & 7 & 8 & 9 & 10 & 11 & $M$ & $S D$ \\
\hline 1. Family income & & & & & & & & & & & & 10.08 & 3.99 \\
\hline 2. Can't make ends meet & $-.42^{* * *}$ & & & & & & & & & & & 3.37 & 1.40 \\
\hline 3. Worries about money & $-.30^{* * *}$ & $.48^{* * *}$ & & & & & & & & & & 2.38 & 1.42 \\
\hline $\begin{array}{l}\text { 4. Parent report of harsh } \\
\text { discipline }\end{array}$ & $-.18^{* * *}$ & $.12^{* *}$ & $.07^{*}$ & & & & & & & & & 2.08 & .86 \\
\hline 5. Adolescent report of harsh & $-09 * *$ & $07^{*}$ & $08^{*}$ & $34^{* * *}$ & & & & & & & & 194 & 78 \\
\hline 6. Adolescent report of conflict & -.05 & .03 & .01 & $.20^{* * *}$ & $.28^{* * *}$ & & & & & & & $\begin{array}{l}1.94 \\
2.29\end{array}$ & $\begin{array}{l}.70 \\
.79\end{array}$ \\
\hline 7. Parent report of conflict & $-.17^{* * *}$ & $.12^{* * *}$ & $.08^{*}$ & $.36^{* * *}$ & $.19^{* * *}$ & $.33^{* * *}$ & & & & & & 2.36 & .82 \\
\hline $\begin{array}{l}\text { 8. Parent involvement in } \\
\text { classroom }\end{array}$ & $.11^{* * *}$ & $-.10^{* *}$ & $-.10^{* *}$ & $-.10^{* *}$ & -.02 & -.00 & $-.09^{*}$ & & & & & 2.35 & 1.97 \\
\hline $\begin{array}{l}\text { 9. Parent involvement in open } \\
\text { house }\end{array}$ & $.18^{* * *}$ & $-.15^{* * *}$ & $-.12 * * *$ & $-.15^{* *}$ & & -04 & $-13^{* *}$ & $41^{* * *}$ & & & & 257 & 241 \\
\hline 10. Parent involvement in PTA & $.13^{* * *}$ & $-.07^{*}$ & -.05 & -.15 & $\begin{array}{r}.04 \\
.00\end{array}$ & $\begin{array}{r}-.04 \\
.02\end{array}$ & -.04 & $.45^{* * *}$ & $.62^{* * *}$ & & & $\begin{array}{l}2.37 \\
2.00\end{array}$ & $\begin{array}{l}2.41 \\
2.33\end{array}$ \\
\hline 11. Seventh grade point average & $.28^{* * *}$ & $-.13^{* * *}$ & $-.13^{* * *}$ & $-.27^{* * *}$ & $-.12^{* * *}$ & $-.22^{* * *}$ & $-.45^{* * *}$ & $.14^{* * *}$ & $.25^{* * *}$ & $.10^{* *}$ & & 3.76 & .84 \\
\hline 12. Eighth grade point average & $.30^{* * *}$ & $-.16^{* * *}$ & $-.07^{* *}$ & $-.25^{* * *}$ & $-.13^{* * *}$ & $-.24^{* * *}$ & $-.46^{* * *}$ & $.16^{* * *}$ & $.25^{* * *}$ & $.09^{* *}$ & $.79^{* * *}$ & 3.72 & .83 \\
\hline
\end{tabular}

Note: Correlations among indicators within constructs are in bold typeface.

${ }^{*} p \leq .05 ;{ }^{* *} p \leq .01 ;{ }^{* * *} p \leq .001$. 
Structural Equation Models

Latent-variable structural equation models were used to test the proposed theoretical model (Figure 1). Maximum likelihood estimates were obtained using LISREL VIII (Joreskog \& Sorbom, 1993a). Since unique dispositions of individual reporters may systematically influence their responses (e.g., parent reports of harsh discipline and conflict), error terms for indicators reported on by the same individual within Wave 1 negative parent-adolescent relationships were allowed to co-vary in these analyses. According to Bank et al. (1990), this procedure reduces the impact of method variance error on the findings. Path coefficients predicted to be nonsignificant were fixed to zero, and other parameters were allowed to be estimated.

In the following analyses, we first tested the proposed versus the alternative model to assure that we properly identified our model. Next, we conducted multigroup comparisons between the African American and European American subsamples and between the single- and two-parent subsamples. Since the multigroup comparisons did not reveal any significant differences between the African American and European American subsamples or between the single- and two-parent subsamples, we then tested the theoretical model (see Figure 1) using the entire sample $(N=617)$.

Proposed versus alternative model. To assure that Wave 1 financial resources only had an indirect association with Wave 1 parenting behaviors through Wave 1 financial strain, and that Wave 1 financial strain only had an indirect association to Wave 2 academic achievement through Wave 1 parenting behaviors, we conducted multigroup comparisons between the proposed model (Figure 1) and alternative model. In the alternative model, we released the paths from Wave 1 family income to Wave 1 parental school involvement and from Wave 1 family income to Wave 1 negative parent-adolescent relationships. We also released the path from Wave 1 financial strain to Wave 2 academic achievement. Consistent with the proposed model, none of these paths was statistically significant. Moreover, a $\chi^{2}$ significance test between the proposed model and the alternative model revealed no statistically significant differences, $p<.05$, in the relations among latent variables, $\Delta$ in $\chi^{2}(\Delta$ in $\mathrm{df})=5.28(3)$. Since releasing these paths did not significantly improve the fit of the model, the proposed model was accepted as the more parsimonious representation of the relations among the constructs (see Bollen, 1989). This supports the theoretical model described above and depicted in Figure 1.

Differences between African American and European
American families. Since analyses of mean differences between African American and European American families showed statistically significant differences (see Table 3), we conducted multigroup comparisons for the structural equations. A $\chi^{2}$ significance test between the African American $(n=387)$ and European American $(n=230)$ subsamples revealed no statistically significant differences, $p<.05$, in the relations among latent variables, $\Delta$ in $\chi^{2}(\Delta$ in df $)=11.07(6)$.

Differences between single-and two-parent families. Analyses of mean differences between single- and two-parent families also revealed statistically significant differences (Table 4). Therefore, we conducted multigroup comparisons for the structural equations. A $\chi^{2}$ significance test between the single- $(n=171)$ and two-parent $(n=446)$ subsamples revealed no statistically significant differences, $p<.05$, in the relations among latent variables, $\Delta$ in $\chi^{2}(\Delta$ in $\mathrm{df})=8.97(6)$. Since $73 \%$ of the single-parent families were African American families, we also conducted multigroup analyses for the single- and two-parent African American families. Again, a $\chi^{2}$ significance test between the single- $(n=121)$ and two-parent $(n=231)$ families revealed no statistically significant differences, $p<$ .05 , in the relations among latent variables, $\Delta$ in $\chi^{2}(\Delta$ in df $)=2.84(6)$. There were not a sufficient number of single-parent European American families $(n=$

Table 3 Mean Differences between African American and European American Families on Indicators

\begin{tabular}{|c|c|c|c|c|c|}
\hline \multirow[b]{2}{*}{ Measures } & \multicolumn{2}{|c|}{$\begin{array}{c}\text { African } \\
\text { American } \\
(n=387)\end{array}$} & \multicolumn{2}{|c|}{$\begin{array}{l}\text { European } \\
\text { American } \\
(n=230)\end{array}$} & \multirow[b]{2}{*}{$t$ Test } \\
\hline & $M$ & $S D$ & $M$ & $S D$ & \\
\hline Family income & 9.72 & 4.29 & 11.34 & 3.72 & $-4.76^{* * *}$ \\
\hline Can't make ends meet & 3.50 & 1.39 & 2.99 & 1.31 & $4.78^{* * *}$ \\
\hline Worries about money & 2.32 & .79 & 2.61 & .80 & $4.18^{* * *}$ \\
\hline $\begin{array}{l}\text { Parent report of harsh } \\
\text { discipline }\end{array}$ & 2.28 & .96 & 1.76 & .52 & $7.30^{* * *}$ \\
\hline $\begin{array}{l}\text { Adolescent report of harsh } \\
\text { discipline }\end{array}$ & 2.05 & .83 & 1.75 & .60 & $4.47^{* * *}$ \\
\hline Parent report of conflict & 2.48 & .84 & 2.11 & .68 & $5.30^{* * *}$ \\
\hline Adolescent report of conflict & 2.48 & .86 & 2.22 & .73 & $3.53^{* * *}$ \\
\hline $\begin{array}{l}\text { Parent involvement in } \\
\text { classroom }\end{array}$ & 2.00 & 3.46 & 2.63 & 2.73 & $-2.47^{*}$ \\
\hline $\begin{array}{l}\text { Parent involvement in open } \\
\text { house }\end{array}$ & 2.29 & 2.13 & 2.95 & 2.36 & $-4.31^{* * *}$ \\
\hline Parent involvement in PTA & 2.07 & 2.09 & 1.92 & 2.10 & -1.95 \\
\hline $\begin{array}{l}\text { Seventy-grade grade point } \\
\text { average }\end{array}$ & 3.49 & .87 & 4.00 & .82 & $-7.44^{* * *}$ \\
\hline $\begin{array}{l}\text { Eighth-grade grade point } \\
\text { average }\end{array}$ & 3.49 & .83 & 4.04 & .76 & $-8.47^{* * *}$ \\
\hline
\end{tabular}

Note: African American = 2; European American $=1$.

${ }^{*} p \leq .05 ;{ }^{* *} p \leq .01 ;{ }^{* * *} p \leq .001$. 
Table 4 Mean Differences between Single- and Two-Parent Families on Indicators

\begin{tabular}{|c|c|c|c|c|c|}
\hline \multirow[b]{2}{*}{ Measures } & \multicolumn{2}{|c|}{$\begin{array}{c}\text { Single- } \\
\text { Parent } \\
\text { Families } \\
(n=171)\end{array}$} & \multicolumn{2}{|c|}{$\begin{array}{c}\text { Two- } \\
\text { Parent } \\
\text { Families } \\
(n=446)\end{array}$} & \multirow[b]{2}{*}{$t$ Test } \\
\hline & $M$ & $S D$ & $M$ & $S D$ & \\
\hline Family income & 6.97 & 3.39 & 11.91 & 3.45 & $15.88^{* * *}$ \\
\hline Can't make ends meet & 3.75 & 1.29 & 3.12 & 1.38 & $-5.70^{* * *}$ \\
\hline Worries about money & 2.14 & .78 & 2.56 & .78 & $-5.77^{* * *}$ \\
\hline $\begin{array}{l}\text { Parent report of harsh } \\
\text { discipline }\end{array}$ & 2.36 & .99 & 1.96 & .78 & $-5.21^{* * *}$ \\
\hline $\begin{array}{l}\text { Adolescent report of harsh } \\
\text { discipline }\end{array}$ & 2.07 & .87 & 1.88 & .71 & -1.89 \\
\hline Adolescent report of conflict & 2.43 & .83 & 2.38 & .82 & -.87 \\
\hline Parent report of conflict & 2.50 & .84 & 2.28 & .77 & $-2.82^{* *}$ \\
\hline $\begin{array}{l}\text { Parent involvement in } \\
\text { classroom }\end{array}$ & 1.73 & 2.20 & 2.68 & 4.02 & $3.37^{* * *}$ \\
\hline $\begin{array}{l}\text { Parent involvement in open } \\
\text { house }\end{array}$ & 1.93 & 1.68 & 2.80 & 2.49 & $4.29^{* * *}$ \\
\hline Parent involvement in PTA & 1.74 & 2.08 & 2.13 & 2.10 & 1.33 \\
\hline $\begin{array}{l}\text { Seventh-grade grade point } \\
\text { average }\end{array}$ & 3.37 & .87 & 3.81 & .86 & $6.43^{* * *}$ \\
\hline $\begin{array}{l}\text { Eighth-grade grade point } \\
\text { average }\end{array}$ & 3.40 & .84 & 3.81 & .81 & $5.99^{* * *}$ \\
\hline
\end{tabular}

Note: Two-parent $=2$; single-parent $=1$.

${ }^{*} p \leq .05 ;{ }^{* *} p \leq .01 ;{ }^{* * *} p \leq .001$.

33) to perform multigroup analyses for single- and two-parent European American families.

Theoretical model. Since multigroup analyses revealed no significant differences between African American and European American families or between single- and two-parent families, all subsequent analyses were performed using the full sample. The results were consistent with the proposed model (Figure 2). As predicted, the standardized path coefficients were significant between Wave 1 financial resources and Wave 1 financial strain, $\beta=-.63, t=-14.84$; between Wave 1 financial strain and Wave 1 parental school involvement, $\beta=-.20, t=-4.32$; and between Wave 1 financial strain and Wave 1 negative parent-adolescent relationships, $\beta=.32, t=6.04$. The standardized path coefficients were also significant between Wave 1 parental school involvement and Wave 2 academic achievement, $\beta=.05, t=2.34$; between Wave 1 negative parent-adolescent relationships and Wave 2 academic achievement, $\beta=-.21, t=-6.68$; and between Wave 1 academic achievement and Wave 2 academic achievement, $\beta=.67, t=27.04$.

As shown in Figure 2, the model fits the data reasonably well, as indicated by a critical $N$ of 341 (Hoelter, 1983) and a goodness of fit index of .97 (Joreskog \& Sorbom, 1993b). The coefficients also demonstrated an acceptable degree of association between indicators and the constructs. Moreover, all of the indicators were statistically significant. As found in other studies, however, the factor loadings of the adolescent reports were slightly lower than those of the parent reports (Conger et al., 1994).

\section{DISCUSSION}

A growing body of research has focused on the relations among economic resources, family processes, and children's development. Although theoretical models linking economic stresses to children's development have been supported by studies with either African American or European American families and either single-parent or two-parent families, the generalizability of these models must be tested empirically using a sample that includes both African American and European American families and both single- and two-parent families, and that reflects a wide range of economic conditions. The participants in this study included an economic cross-section of single- and two-parent African American and European American families with adolescent children. Using this sample, the present study tested the empirical adequacy of a mediational model of financial strain, parenting behaviors, and adolescents' academic achievement for both African American and European American families and both single- and two-parent families. To our knowledge, this is the first study to test empirically the equivalence of this model for different ethnic groups and family structures.

The findings were supportive of the theoretical model (Figure 1). Family income influenced negative parent-adolescent relationships and parental school involvement only through parents' sense of financial strain. These results support earlier research, which showed that seemingly objective measures of hardship, such as low income, affect behavior only to the extent that they create economic strain and worries (Conger et al., 1997, 1992, 1994; Elder et al., 1995; Harold-Goldsmith et al., 1988; McLoyd et al., 1994; Simons et al., 1992). We also found that parents' sense of financial strain increased the likelihood of negative parent-adolescent relationships and adversely affected parental school involvement. These findings are consistent with those of previous studies (e.g., Conger et al., 1997, 1992, 1994; Elder et al., 1995; Harold-Goldsmith et al., 1988; McLoyd et al., 1994), which indicated that distress associated with low income undermines the capacity for effective parenting. Our study extended the scope of this research, demonstrating that negative parent-adolescent relationships and parental school involvement mediated the 


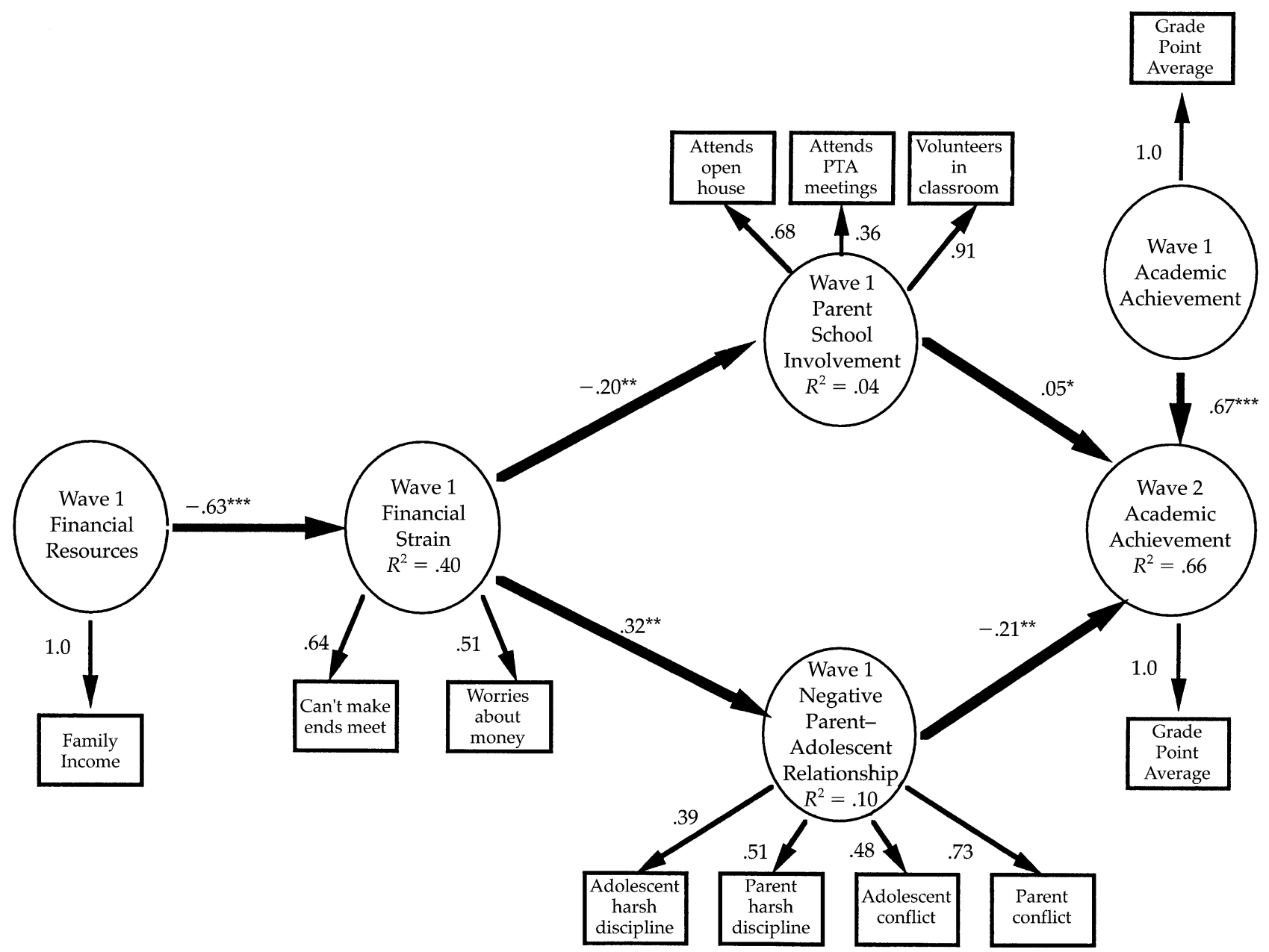

Figure 2 Maximum likelihood estimation of the model. Residual for indicators involving the same reporters were allowed to correlate across constructs (not shown). For the model, $\chi^{2}(45, N=617)=226.13$, GFI $=.97$, AGFI $=.94, \mathrm{NFI}=.93$, and critical $N=$ $341.00\left(R^{2} \mathrm{~s}\right.$ are reported in the circles).

relation between financial strain and adolescents' academic achievement.

Although there are reasons in the previous literature to expect possible ethnic differences in a mediational model of financial strain, parenting behaviors, and adolescent academic achievement, we found no statistically significant differences in the structural latent-variable models between African American and European American families. Although differences may seem apparent in studies that confound income level and ethnicity, such disparities may not arise when examining a sample that includes a wide economic distribution of both African American and European American families. In our study, within both ethnic subsamples, the families ranged in economic status from those living below the U.S. poverty threshold to those in the upper-income brackets. As a result, the African American subsample was not over- represented in the lower income bracket and both subsamples contained sufficient variability to test the proposed model. Furthermore, since the African American and European American families represented an economic cross-section, it is more likely that they lived in comparable neighborhoods and had access to similar community resources than may be true in studies that compare African American and European American samples with quite different economic characteristics. As this county had open school enrollments, families from the ethnic subsamples were also more likely to have sent their children to similar schools than were families in more typical ethnicgroup comparative studies. Thus, our results indicate that African American and European American families with comparable economic resources may respond similarly to the effects of economic strain. They also suggest that the ethnic-group differences 
found in other studies may reflect their economic more than their cultural histories.

We also found no differences in the proposed model between the single- and two-parent families in either the full sample or African American subsample. As with the African American and European American families, these findings are particularly informative when they are considered in the context of where the participants live. These results indicate that single- and two-parent families who represent an economic cross-section and are likely to have access to comparable economic resources may respond similarly to the effects of financial strain. Although single mothers are at greater risk of psychological distress and anxiety than are parents from other marital status groups (McLoyd, 1990), economic resources (e.g., safe neighborhoods and employment opportunities) may help buffer their ability both to cope with economic worries and to provide effective parenting. Moreover, the impact of single parents' economic distress on adolescents' development may be reduced if adolescents have access to high-quality support systems (e.g., schools and community programs).

The results of this study support previous research (e.g., Conger et al., 1992, 1994; McLoyd, 1990; McLoyd et al., 1994) suggesting that in both African American and European American families, and in both singleand two-parent families, economic stresses affect children's developmental outcomes indirectly through family processes. Moreover, these findings provide important insight into the processes through which economic resources influence adolescents' academic achievement. For example, the results of this study suggest that both supportive and nonsupportive parenting practices are significant links between financial strain and adolescents' grade point average.

Several limitations of this study and some caveats should be noted. First, our model is not intended to be exhaustive. It does not allow for important predictors of adolescents' academic achievement such as school characteristics, neighborhood context, and peer relationships (e.g., Brooks-Gunn, Duncan, Klebanov, \& Sealand, 1993; Duncan, 1994; Rist, 1970; Rutter, 1983; Steinberg, Dornbusch, \& Brown, 1992). However, our model was not intended to explain all of the variation in adolescents' academic achievement. Rather, our study specifically tested a mediational model of family processes linking financial strain to adolescents' achievement for both African American and European American families and both single- and twoparent families. Testing the equivalence of a model that predicts adolescents' academic achievement for these different groups is a worthwhile endeavor for future studies. Our model was also limited to a sin- gle measure of academic achievement (i.e., grade point average). Although grades are the primary criteria for continuation through the educational system in that they determine grade advancement, classes in high school, and college admittance, other indices of achievement (e.g., standardized test scores and school absences) should be considered in future studies.

Second, our sample is not completely random, and does not include an over-representation of families experiencing severe economic problems. It does represent an economic cross-section of African American and European American families and single- and twoparent families, and it is also one of the few samples representing a large number of middle- to upperincome African American families.

Third, we had a substantial reduction in sample size due to attrition from Wave 1 to Wave 2 and listwise deletion of data, but, the amount of variance in sample characteristics accounted for by this attrition was quite modest. Moreover, the nature of the bias introduced by attrition (i.e., a disproportionate loss of highly stressed families) should yield less support for our hypothesis, making it likely that our results underestimated the magnitude of the associations found for the predicted paths in our model.

Finally, although the paths between variables in our model may imply causality, this study only tested the extent to which the observed relations among variables can be predicted from our hypothesized model. The use of longitudinal data controlling for prior levels of achievement strengthens our confidence in the proposed causal directions. The measurement of the dependent variable at two or more time points allows us to rule out the rival hypothesis that the dependent variable causes the independent variable rather than vice versa. It also greatly reduces the threat of spuriousness.

Despite these limitations, our model is still restricted to measures of a limited duration and developmental time frame (i.e., adolescence). Recent studies demonstrate that earlier (birth to age 5), more persistent poverty has more adverse effects than does later, more transitory poverty on children's educational outcomes (Duncan, Yeung, Brooks-Gunn, \& Smith, 1998; Korenman et al., 1995; Smith, Brooks-Gunn, \& Klebanov, 1997). Research also suggests that the duration and timing effects of poverty may vary between different ethnic groups and different family structures. For instance, Duncan et al. (1998) not only found that poverty during the first 5 years of life contributed more to the number of school years completed than did poverty during middle childhood and adolescence, but that the differential impact of income in terms of childhood stage was particularly strong for 
African Americans as compared to European Americans. There is also controversy about the relative importance of such income effects on children's and adolescents' outcomes. According to Mayer (1997), the effects of income on children's development may be overestimated due to the variance family income and child outcomes both share with unmeasured parental characteristics. For these reasons, future studies not only should test model equivalence for families living in persistent versus transitory poverty and for children experiencing poverty at different developmental time points, but should also consider different approaches for assessing the relative importance of income and parental characteristics in shaping children's development.

\section{ACKNOWLEDGMENTS}

The funding for this research was provided by grants from the National Institutes for Child Health and Human Development and the MacArthur Research Network on Successful Adolescent Development in High Risk Settings to Jacquelynne S. Eccles and Arnold Sameroff. We thank the following people for their help in data collection and data processing: Elaine Belansky, Todd Bartko, Nick Butler, Diane Early, Kari Fraser, Ariel Kalil, Linda Kuhn, Sarah Lord, Karen McCarthy, Oksana Malanchuk, Alice Michael, Steve Peck, Kate Rosenblum, Sherri Steele, and Cindy Winston.

\section{ADDRESSES AND AFFILIATIONS:}

Corresponding author: Leslie Morrison Gutman, Institute for Social Research, University of Michigan, 426 Thompson Street, P.O. Box 1248, Ann Arbor, MI 48106-1248; e-mail: lmgutman@umich.edu. Jacquelynne S. Eccles is also at the University of Michigan.

\section{REFERENCES}

Bank, L., Dishion, T. J., Skinner, M., \& Patterson, G. R. (1990). Method variance in structural equation modeling: Living with glop. In G. R. Patterson (Ed.), Depression and aggression in family interaction (pp. 247-279). Hillsdale, NJ: Erlbaum.

Baumrind, D. (1972). An exploratory study of socialization effects on black children: Some black-white comparisons. Child Development, 43, 261-267.

Bollen, K. (1989). Structural equations with latent variables. New York: Wiley.

Brooks-Gunn, J., Duncan, G., Klebanov, P. K., \& Sealand, N. (1993). Do neighborhoods influence child and adolescent development? American Journal of Sociology, 99, 353-395.
Brooks-Gunn, J., Duncan, G. J., \& Maritato, N. (1997). Poor families, poor outcomes: The well-being of children and youth. In G. J. Duncan \& J. Brooks-Gunn (Eds.), Consequences of growing up poor (pp. 1-17). New York: Russell Sage Foundation.

Carnegie Council on Adolescent Development. (1995). Great transitions: Preparing adolescents for the new century. New York: Author.

Clark, R. (1983). Family life and school achievement: Why poor black children succeed or fail. Chicago: University of Chicago Press.

Comer, J. P. (1980). School power. New York: Free Press.

Conger, R. D., Conger, K. J., \& Elder, G. H. (1997). Family economic hardship and adolescent adjustment: Mediating and moderating processes. In G. J. Duncan \& J. Brooks-Gunn (Eds.), Consequences of growing up poor (pp. 288-310). New York: Russell Sage Foundation.

Conger, R. D., Conger, K. J., Elder, G. H., Lorenz, F. O., Simons, R. L., \& Whitbeck, L. B. (1992). A family process model of economic hardship and adjustment of early adolescent boys. Child Development, 63, 526-541.

Conger, R. D., Ge, X., Elder, G. H., Lorenz, F. O., \& Simons, R. L. (1994). Economic stress, coercive family processes, and developmental problems of adolescents. Child Development, 65, 541-561.

Conger, R. D., Lorenz, F. O., Elder, G. H., Melby, J. N., Simons, R. L., \& Conger, J. C. (1991). A process model of family economic pressure and early adolescent alcohol use. Journal of Early Adolescence, 11, 430-449.

Dodge, K. A., Pettit, G. S., \& Bates, J. E. (1994). Socialization mediators of the relations between socioeconomic status and child conduct problems. Child Development, 65, 649665.

Dornbusch, S. M., Ritter, P. L., Leiderman, P. H., Roberts, D. F., \& Fraleigh, M. J. (1987). The relation of parenting style to adolescent school performance. Child Development, 58, 1244-1257.

Duncan, G. (1994). Families and neighborhoods as sources of disadvantage in the schooling decisions of White and Black adolescents. American Journal of Education, 103, 20-53.

Duncan, G., Yeung, W., Brooks-Gunn, J., \& Smith, J. (1998). How much does childhood poverty affect the life chances of children? American Sociological Review, 63, 406-423.

Eccles, J. S., \& Harold, R. (1993). Parent-school involvement during the early adolescent years. Teachers College Record, 94, 568-587.

Elder, G. H. (1974). Children of the Great Depression. Chicago: University of Chicago Press.

Elder, G. H., Eccles, J. S., Ardelt, M., \& Lord, S. (1995). Innercity parents under economic pressure: Perspective on the strategies of parenting. Journal of Marriage and Family, $57,771-784$.

Elder, G. H, Van Nguyen, T., \& Caspi, A. (1985). Linking family hardship to children's lives. Child Development, $56,361-375$.

Epstein, J. L. (1987). What principals should know about parental involvement. Principal, 66, 6-9.

Epstein, J. L. (1990). School and family connections: Theory, research, and implications for integrating sociologies of 
education and family. Marriage and Family Review, 15, 99126.

Furstenberg, F., Cook, T., Eccles, J. S., Elder, G. H., \& Sameroff, A. (1999). Managing to make it. Chicago: University of Chicago Press.

Harold-Goldsmith, R., Radin, N., \& Eccles, J. S. (1988). Objective and subjective reality: The effects of job loss and financial stress on fathering behaviors. Family Perspective, 22, 309-326.

Hess, R., \& Holloway, S. (1984). Family and school as educational institutions. In R. D. Parke (Ed.), Review of child development research (Vol. 7, pp. 179-222). Chicago: University of Chicago Press.

Hoelter, J. W. (1983). The analysis of covariance structures: Goodness-of-fit indices. Sociological Methods and Research, 11, 325-344.

Joreskog, K. G., \& Sorbom, D. (1993a). Lisrel VIII: User's reference guide. Chicago: Scientific Software International.

Joreskog, K. G., \& Sorbom, D. (1993b). Lisrel VIII: Structural equation modeling with the SIMPLIS command language. Chicago: Scientific Software International.

Korenman, S., Miller, J., \& Sjaastad, J. (1995). Long-term poverty and child development in the United States: Results from the NLSY. Children and Youth Services Review, 17, 127-155.

Lee, V., \& Croninger, R. (1994). The relative importance of home and school in the development of literacy skills for middle-grade students. American Journal of Education, 102, 286-329.

Lempers, J. D., Clark-Lempers, D., \& Simons, R. L. (1989). Economic hardship, parenting, and distress in adolescence. Child Development, 60, 25-39.

Mayer, S. (1997). What money can't buy: Family income and children's life chances. Cambridge, MA: Harvard University Press.

McLoyd, V. C. (1990). The impact of economic hardship on black families and children: Psychological distress, parenting, and socioeconomic development, Child Development, 61, 311-346.

McLoyd, V. C. (1998). Socioeconomic disadvantage and child development. American Psychologist, 53, 185-204.

McLoyd, V. C., Jayaratne, T. E., Ceballo, R., \& Borquez, J. (1994). Unemployment and work interruption among African American single mothers: Effects on parenting and socioemotional functioning. Child Development, 65, 562-589.

Patterson, G. (1982). A social learning approach to family intervention. Coercive Family Process (Vol. 3). Eugene, OR: Castalia.

Rist, R. (1970). Student social class and teacher expectations: The self-fulfilling prophecy in ghetto education. Harvard Educational Review, 40, 411-451.

Rutter, M. (1983) School effects on pupil progress: Research finding and policy implications. Child Development, 54, $1-29$.

Simons, R. L, Lorenz, F. O., Conger, R. D., \& Wu, C. (1992). Support from spouse as mediator and moderator of the disruptive influence of economic strain on parenting. Child Development, 63, 1282-1301.

Smith, J., Brooks-Gunn, J., \& Klebanov, P. (1997). Consequences of living in poverty for young children's cognitive and verbal ability and early school achievement. In G. J. Duncan \& J. Brooks-Gunn (Eds.), Consequences of growing up poor (pp. 132-189). New York: Russell Sage Foundation.

Steinberg, L., Dornbusch, S. M., \& Brown, B. B. (1992). Ethnic differences in adolescent achievement: An ecological perspective. American Psychologist, 47, 723-729.

U.S. Bureau of the Census. (1996). Statistical abstract of the United States: 1996. Washington, DC: U.S. Government Printing Office.

Wilson, W. J. (1987). The truly disadvantaged: The inner city, the underclass, and public policy. Chicago: University of Chicago Press. 